Vol.16, No.60, JULY 2021, 692-711

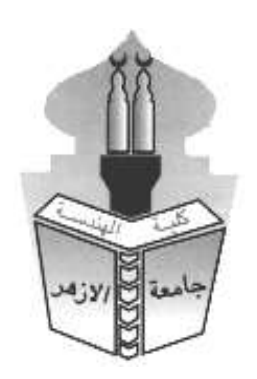

\title{
EVOLUTIONARY ALGORITHMS BASED TUNING PI CONTROLLER FOR OPTIMAL MICROGRID OPERATION
}

\author{
Amany Hamdy ${ }^{1, *}$, Hany M. Hasanien ${ }^{2}$, A.Y Abdelaziz ${ }^{3}$ \\ ${ }^{1}$ Electrical Power \& Machines, Faculty of Engineering, Ain Shams University, Cairo, Egypt. \\ ${ }^{2}$ Electrical Power \& Machines. Dept., Faculty of Engineering, Ain Shams University, Cairo, Egypt. \\ ${ }^{3}$ Electrical Power \& Machines. Dept., Faculty of Engineering, Ain Shams University, Cairo, Egypt. \\ *Corresponding Author E-mail: dr.amanyhamdy13@gmail.com
}

Received: 14 March 2021 Accepted: 01 June 2021

\begin{abstract}
A decentralized control scheme for both on-grid and off-grid connected cascaded modular decentralized Energy Generation (DEG) and two-level converter, which depends on the Proportional-Integral (PI) controller. The PID controller family is a particular control structure that became the most universally used in industrial control. They have proven to be robust in control of many important industrial applications due to their good performance and ease of implementation. The controller performance mostly depends on tuning, which required selecting appropriate values for the controller gain to reach a trade-off between performance and reliability. This paper demonstrates a case study, in which we use an optimization algorithm based on Harmony Search (HS) to select automatically the controller parameters, which minimizes our predefined objective function. Differs from the objective functions are used commonly to evaluate the performance of the controller. The result obtained will be compared with the ones obtained by using the genetic algorithm (GA) and the particle swarm optimization (PSO). Simulations are conducted using MATLAB/Simulink software. The system is tested under different operating conditions as per the following conditions: 1) the steady-state operation at on-grid connected mode.2) System Transfer from on-grid connected to off-grid, and3) System expose three lines to earth fault in an off-grid mode. The objective is to verify the effectiveness of the proposed algorithm and the results show that the performance of the proposed approach provides a better dynamic response and surpasses the other control techniques.
\end{abstract}

KEYWORDS: Decentralized Energy Generation (DEG), Genetic Algorithms (GA), Harmony Search (HS), Particle Swarm Optimization (PSO), and Integral Square Error (ISE). 


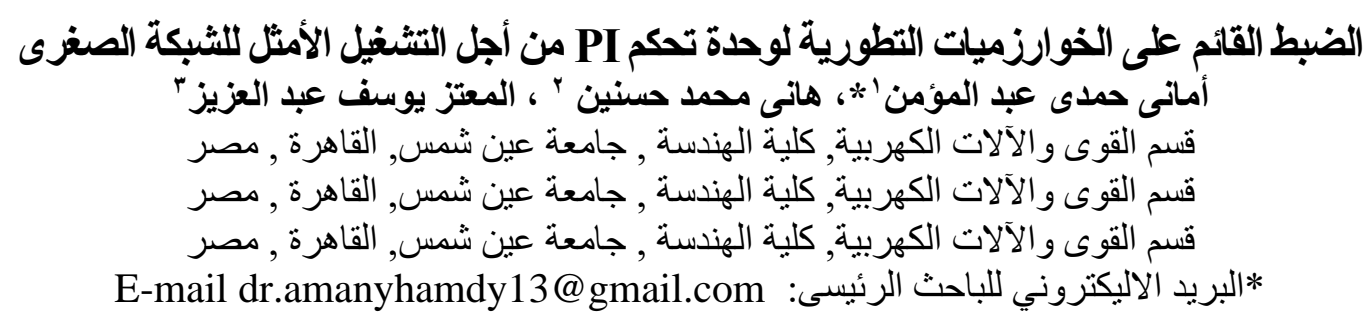

الملخص

مخطط تحكم لامركزي لكل من المحو لات المعيارية المتتالية المتصلة بالثبكة وخارج الثبكة ، و التي تعتمد على وحدة

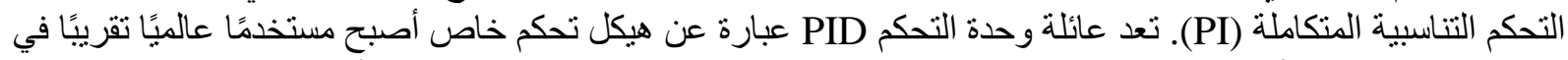

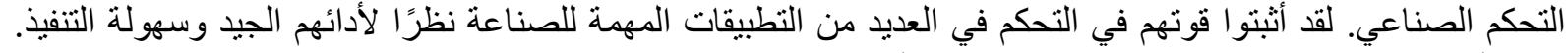

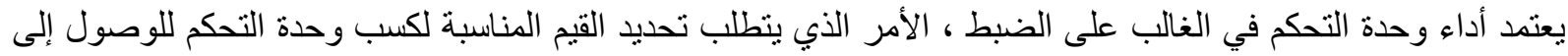

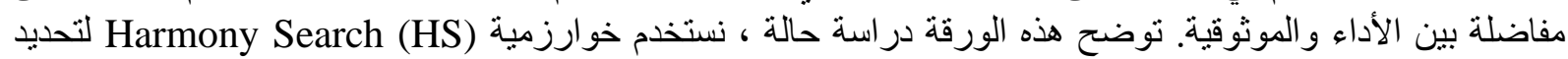

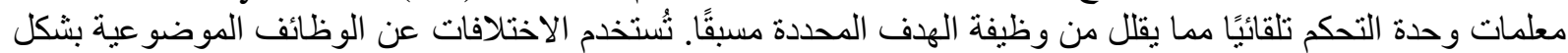

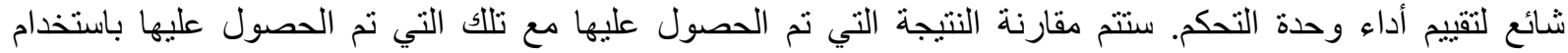

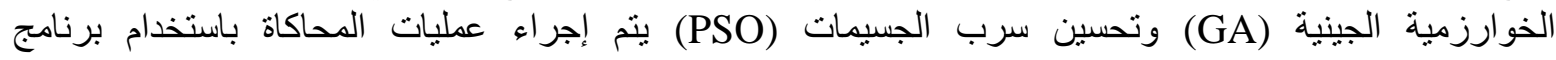
المATLAB/Simulink

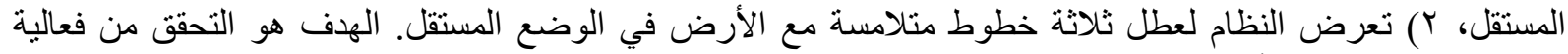
الخوارزمية المقترحة. تُظهر النتائج أن أداء النهج المقترح يوفر استجابات ديناميكية أفضل ويتفوق على تقنيات التحكم الأخرى.

الكلمات المفتاحية : التوليد اللامركزي للطاقة (DEG), (DEG), الخوارزمية الجينية (GA), بحث التناغم (HS), تحسين سرب

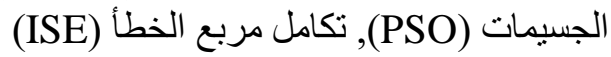

\section{INTRODUCTION}

A modern power system contains three basic components generation, transmission line or cable, and distribution as shown in Fig. 1[1]. Controlling the dynamic behavior of interconnected electricity systems presents a great operational challenge. The engineering of power systems is a subdomain of energy engineering deals with the shortages of energy resources, higher costs of power generation, safety issues, and environmental concerns.

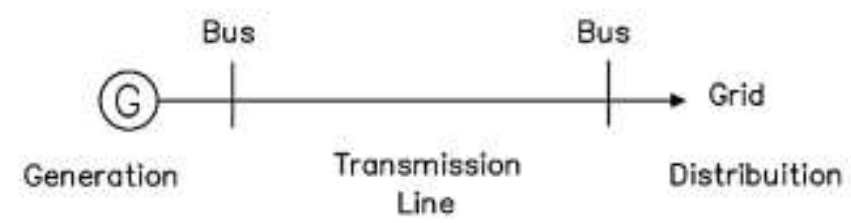

Fig.1 Schematic of basic diagram of a power system.

The modern power system affected by highly stressed conditions: [2]

- Keep the balance between generation and demand consistently.

- Adjust generation reactive power to provide the voltage levels within limits on demand. 
- Monitor power flow over the network.

- The ability to provide system stability.

- Operate the system so that it can maintain stability even if a component fails.

- Plan, design, and maintain the system to function reliably.

- Get ready to deal with emergencies.

The primary requirement for economic development is high quality and clean electrical energy. Due to large-scale industrialization, the electricity demand has risen multi-pronged [3]. Due to growth in demand, deregulation, the cost of generating power systems, which is still too high and has no standard methodology for measuring benefits, (such as social or environmental benefits). Therefore, to solve their problems, power utilities often need new technologies [4]. One ideal solution was the trend to use a local energy grid with a control capability, which means that it can disconnect and operate independently from the grid. It has called a microgrid, which is not a new idea but used in the very beginning of rural electrification, the economic benefits of microgrids associated with large power plants have led to current power system structures. Decentralized Generation (DG) is the major equipment in the microgrid. It is defined as the production of electricity at or near the point of use, regardless of scale, technology, or fuel used, both on-grid and off-grid [5].

A control strategy based on the output voltage and frequency regulation to control the real and reactive power delivered from a DG to a local load. The control strategy relies on two focuses to implement it. [6]

1- Proposed cascaded converter is shown in Fig. 2. This topology is constructed by supplying a two-level converter from a DC source. The converter is modeled with IGBT/diode pairs controlled by firing pulses produced by a PWM generator.

2- PI controller is preferred due to its simplicity and reliability as well as good performance [7]. Currently, the PI is widely used in industrial applications due to its simple structure, easy design, and low cost, as in Fig. 3 shown The PI controller proposes a large boundary of stability; eliminates forced oscillations and steady-state error resulting in the operation of the controller on-off. PI is not the best controller. It is only the most common controller, because many, or maybe even most, applications are simple and do not need so much. [8]

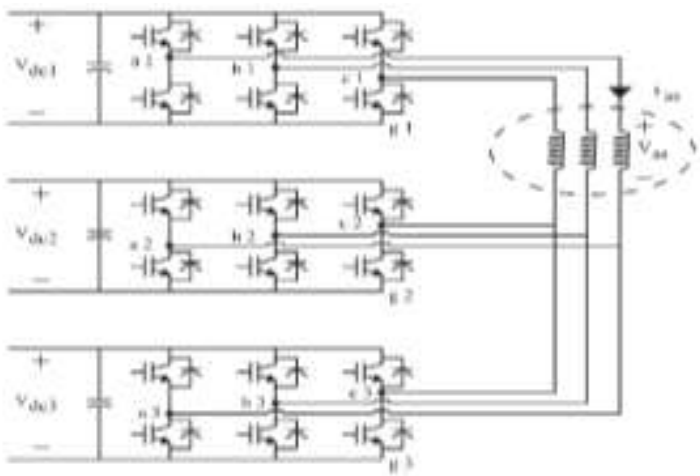

Fig.2 The proposed cascaded converter

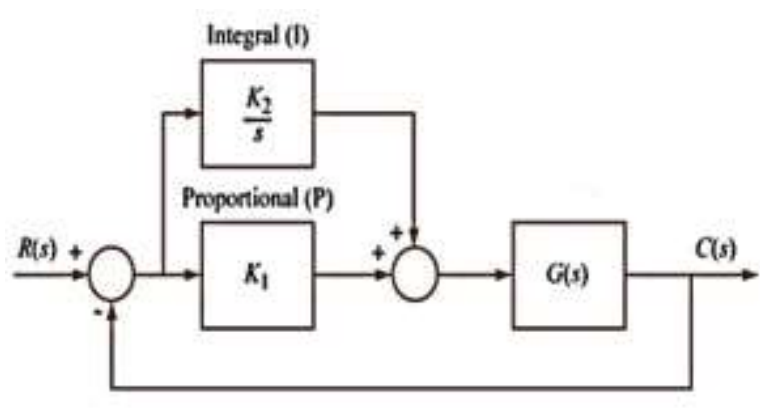

Fig.3 Schematic diagram of PI controller

The controller output 
$\mathrm{u}(\mathrm{t})=K p \cdot e(t)+\mathrm{Ki} \int e(t) d t$

Optimization is the way to ensure that the system is as efficient or powerful as possible [9]. Optimization aims at finding the best options to achieve particular goals and circumstances. Most frequently, problems of engineering optimization involve objective, non-linear, undefined functions with severe limitations on equality and inequality side by side with different Types of decision variables. Consequently, it is becoming increasingly difficult to solve optimization problems using conventional approaches. Algorithms of meta-heuristic optimization may be useful alternatives to solve the complexity of complex optimization problems [10]. The Algorithm for PI Control is used in process sectors to control almost every loop. HS is an experimental enhancement based on a music algorithm.it inspired by the observation that the goal of music is to find the state of perfect harmony. This music harmony is similar to finding the optimal performance in the optimization process [11]. The evolutionary algorithm, like GA is randomly re-inserted search algorithms developed by emulating Natural selection mechanisms and natural genetics [12]. PSO is one of the techniques for improving direct research that relies on colonial behavior or a squadron of insects, such as ants, white ants, bees, and wasps. [13].

This paper discusses the implementation of GA, PSO, and HS technologies based on the transfer function selected in the vector control scheme as the control method of the inverter that is based on the PI controller. The Suggested control technique was validated using simulation results made using the MATLAB/SIMULINK software [14]. The system tested under operating conditions, which switched from a connected network to a standalone mode system. The paper is structured as follows:

In Section 2, the system is modeled. The control methodology is detailed in section 3. In Section 4, the case study using HS, GA, PSO algorithm, and objective function are discussed. In Section 5, the simulation results and the comparative evaluation stage between HS, GA, and PSO techniques are demonstrated. Finally, the conclusions are stated.

\section{MODEL FORMULATION}

A schematic diagram of a three different DG system connects via a two-level converter to a utility grid as Fig. 4. The three DGs and the grid are associated with a point of common coupling (PCC) to feed a local load. Each DG unit represented by a DC voltage source, a PWM, and a series filter. A delta-star step-up transformer is a principal link between the three DGs and the grid. A three-phase parallel RLC network model is the local load, a Parallel RLC is a complex load class when the inductance and capacitance of load are set on the frequency system and the three DGs deliver their total power. 
Evolutionary Algorithms Based tuning PI Controller for Optimal Microgrid Operation

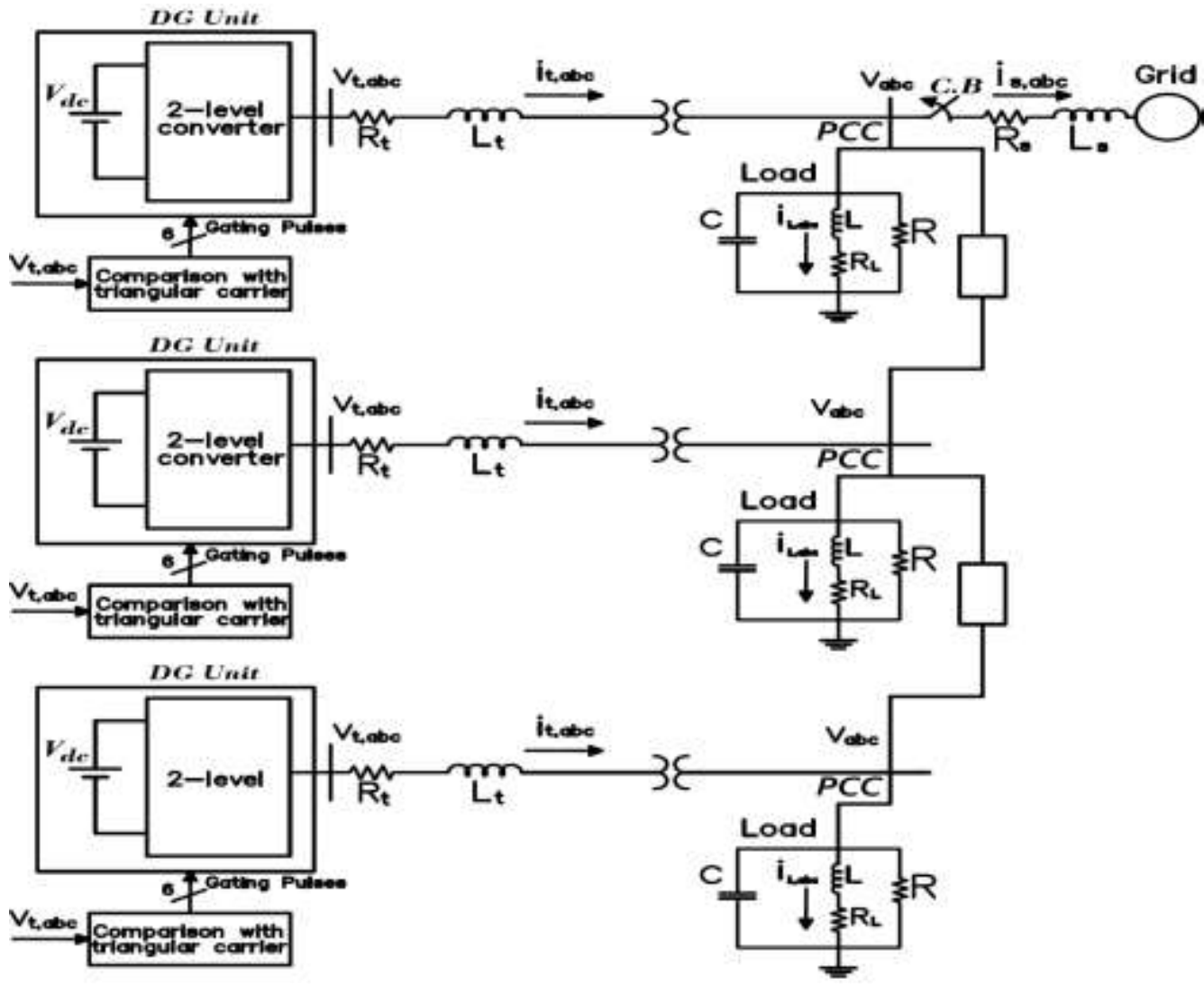

Fig.4 Schematic of the three DG's microgrid.

Data of the three DGs, the Grid, and the rated load values that consider in this analysis shown in Table 1.

Table 1: Parameter Values Of DEGs

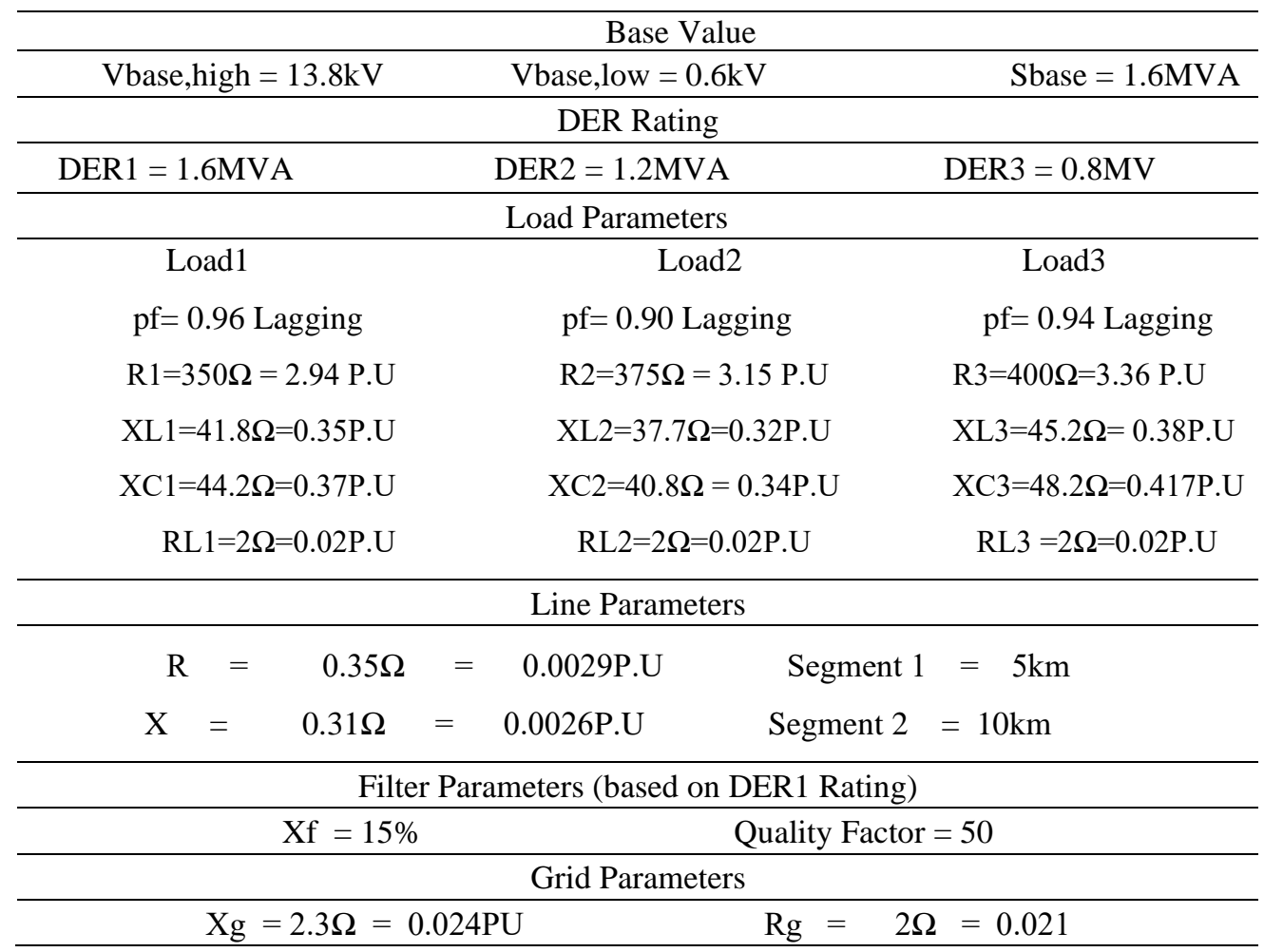




\section{CONTROL METHODOLOGY}

The voltage source converter (VSC) technique uses the control loop for each of the three DEGs in the microgrid [15]. For on-grid connected mode, the goal is to control the active and reactive power supplied to and from the grid [16]. Since the converter does not dictate the grid voltage, this is achieved by controlling the current supplied by the converter to the grid as shown in Fig 5.a. The control scheme requires an accurate phase value of the fundamental component of the grid voltage. This value is obtained from a phase-locked loop (PLL) which has the grid voltage as its input and generates the frequency and currents in the direct and quadrature axes (Id, Iq) as its outputs. Voltage angle $\delta$ and magnitude $|\mathrm{V}|$ of each DG.

$\mathrm{Pi}=\sum_{k=1}^{N}|\mathrm{Vi}||\mathrm{Vk}|(\mathrm{GikCos} \delta \mathrm{ik}+\operatorname{BikSin} \delta \mathrm{ik})$

$\mathrm{Qi}=\sum_{k=1}^{N}|\mathrm{Vi}||\mathrm{Vk}|(\mathrm{GikSin} \delta \mathrm{ik}+\operatorname{Bik} \operatorname{Cos} \delta \mathrm{ik})$

It is quite the opposite, for off-grid connected mode as shown in Fig 5.b the goal is to control the terminal voltages of direct and quadrature axis components $(\mathrm{Vd}, \mathrm{Vq})$. The output voltage is specified at the utility level as in [17], which clearly defines Vrms to be within $\pm 5 \%$ of the nominal voltage. The control structure commonly used to achieve these is the two-loop control [18], [19], with an inner current and outer voltage loop as shown in Fig 5.c,d. An internal oscillator is used to control the frequency of the system in an inner loop controller. The internal oscillator frequency is set at the nominal frequency of the system $\omega 0$. So as the frequency of voltage and current signals within the off-grid connected is predetermined in $\omega 0$. PWM the generator produces a triangular signal with constant value and compared to the reference voltages.

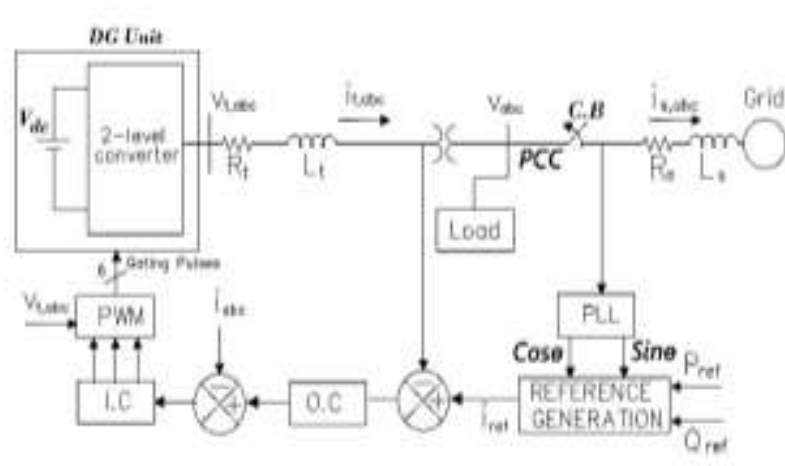

a) Direct Grid Control Architecture Based Each DG On-Grid connected.

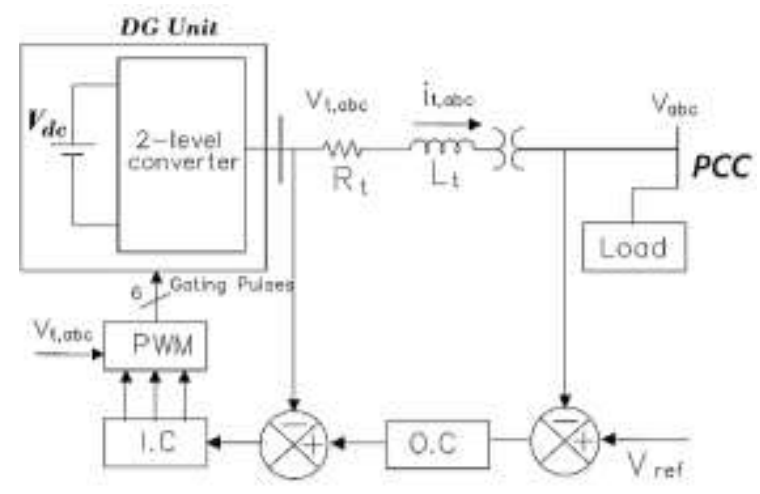

b) Conventional two-loop architecture for each DG Off-Grid. 


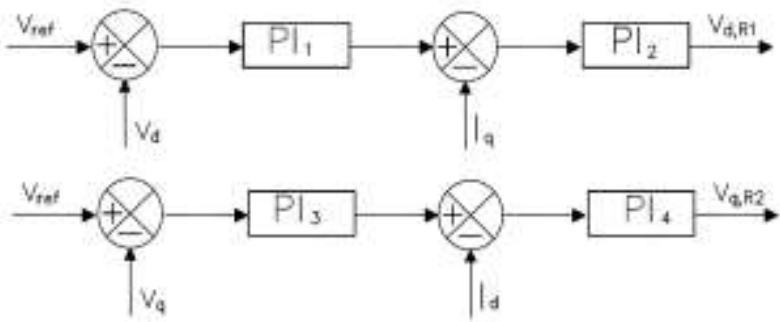

c) Outer Controlling (O.C) Loop.

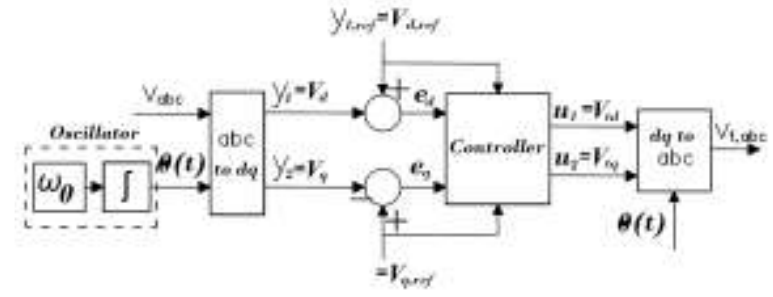

d) Inner Controlling (I.C) Loop

Fig. 5: The Mechanism for a voltage source converter (VSC) technique.

As the vector control technique offers decoupled control for fast dynamics, it makes the realization of system control in form of a cascade structure, with twelve PI controller loops in the cascade, outer control loop, and inner current control. The design of control loops starts from the inner (fast) loop and proceeds to the outer (slow) loop.

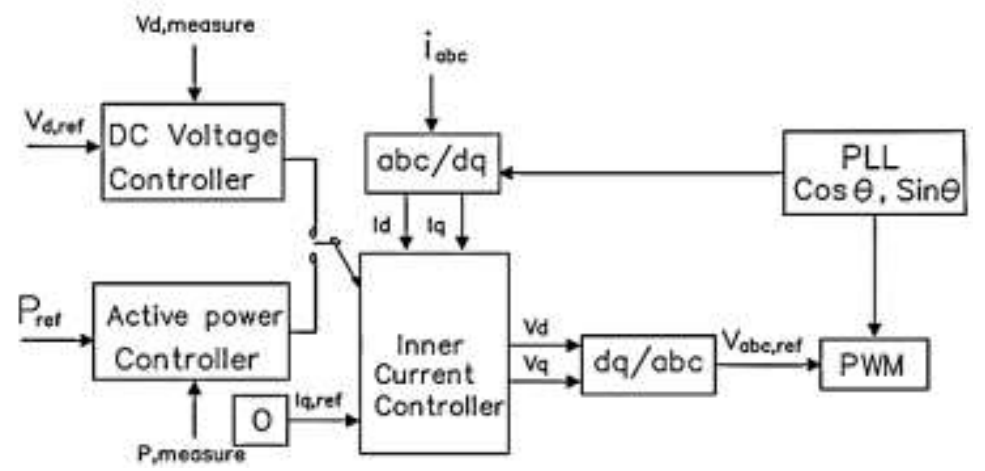

Fig. 6: The Cascaded Vector Control Block Diagram.

\section{CASE STUDY}

\subsection{Outline of Modelling}

The system is modeled using MATLAB/Simulink software. The proposed control strategy is extensively verified using the simulation results under different operating conditions. Three proposals applied with the HS algorithm and to check the validity of these cases, it should be tested with different well-known optimization algorithms that were used widely in the literature. The effectiveness of the proposed controller is verified by comparing its results with that obtained using the GA, and PSO algorithm-based PI controller. The three proposals: 1) the steady-state operation at on-grid connected mode.2) System Transfer from on-grid connected to off-grid, and3) System expose to three lines to earth fault in an off-grid mode. For each simulation, proposal calculations are carried out. MPUS, MPOS, Ts, Ess, which represents the Minimum Percentage of Undershoots, Maximum Percentage Overshoots, settling time, and steady-state error respectively.

\subsection{Meta-Heuristic Optimization}

Iterative simulation-based techniques have been implemented, facilitating the use of restricted computation time and memory and without needing any complex derivatives to find suitable solutions. Many meta-heuristic algorithms have been developed that combine rules 
and randomness to imitate natural phenomena, including ant colony optimization (ACO), genetic algorithm (GA), particle swarm optimization (PSO), and such simulated-based methods of meta-heuristic research have powerful research capabilities enabling them to mitigate the many shortcomings of conventional mathematical analysis. For example, harmony search (HS) algorithms [20]. An algorithm that simulates a biological process such as mutation, recombination, and a natural fit. To find the optimal design under clear constraints. The General framework of the meta-heuristic Algorithm could be derived in Fig.7.

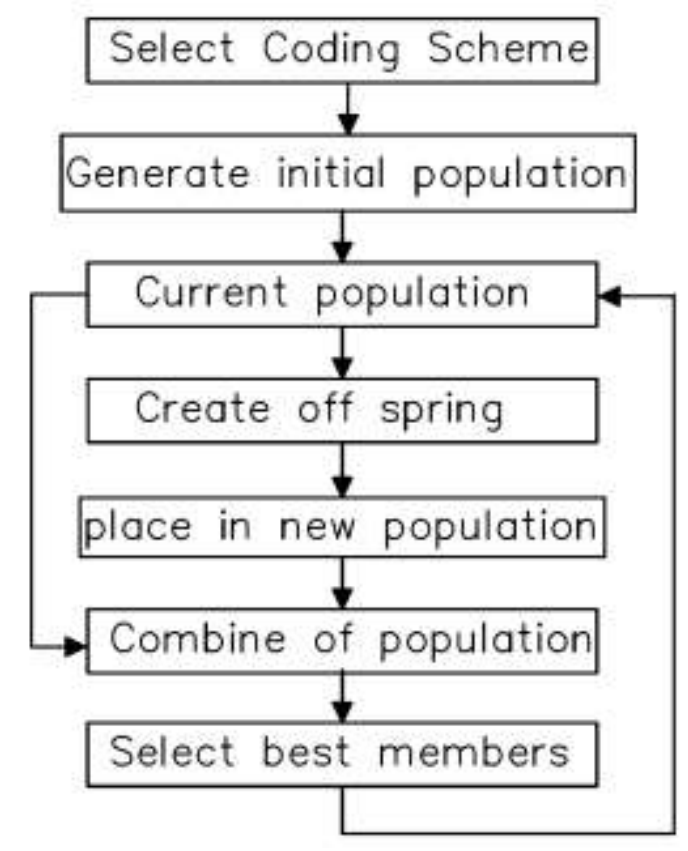

Fig. 7: Meta-Heuristic Algorithm.

\subsubsection{Genetic Algorithms (GA)}

In each generation, the genetic factors are applied to individuals selected from the existing population for shaping a new population [21]. In general, the three major genetic factors:

1) Reproduction

Copied selected individuals from the current population without modification can generate a portion of the new population. Already established populations may also choose new populations. Varieties of other methods of selection are available and it is up to the user to choose the right one for each application. All methods of selection are based on the same theory.

2) Crossover

It is acting as a binary operator; in general, new individuals are generated as the offspring of two parents. Within each parent's chromosome, one or more so-called crossover points (usually at random) are selected. The parts denoted by the crossover points between the parents are then overlapped. The individuals who generated are the offspring. There are several crossover styles beyond one point and multiple point crossovers.

3) Mutation

By making modifications to one chosen individual, a new individual is created. That can be consist of modifying one or more values or adding/deleting parts of the representation. The 
mutation is a source of variability in GA, and the rate of very large mutations leads to less efficient development, except for the case of simple problems particularly .

The speed of convergence can be controlled by using different likelihoods for applying these factors. Crossover and mutation factors need to be carefully configured, as their choice contributes greatly to the success of the genetic algorithm as a whole. Intending to optimize the PI controller parameters, the chosen parameters are key in the performance as follows in Table 2.

Table 2: Parameters Settings for GA

\begin{tabular}{cc}
\hline Parameters & Values \\
\hline Population size & 20 \\
\hline Number of iterations & 500 \\
\hline Mutation Rate & 0.1 \\
\hline Crossover Rate & 0.85 \\
\hline
\end{tabular}

The GA's illustrative flowchart Implementation of algorithms is presented in Fig. $\mathbf{8 .}$

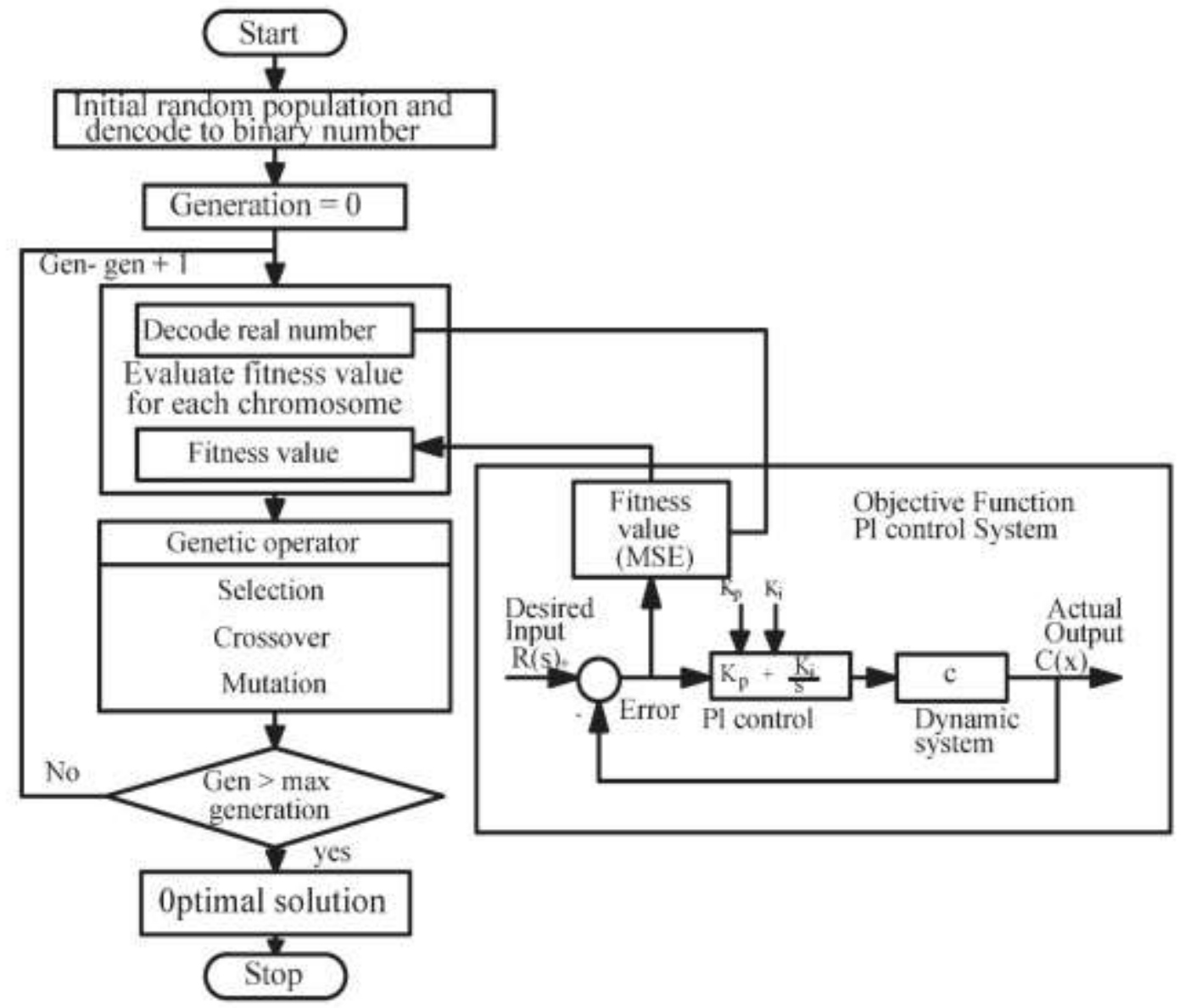

Fig. 8: Flow Chart of the General GA Algorithm. 


\subsubsection{Particle Swarm Optimization (PSO)}

PSO is a random optimization method that focuses on motivating the population's inspiration from an activity of bird or fish flocking [22]. PSO develops from experience and uses it to solve optimization problems. In PSO, in the search space, every single solution is a "bird" or "particle". Particles move with their knowledge and experience of their nearest particles in a multi-dimensional search field. Each particle has fitness values and velocities which performance is evaluated by a predefined fitness function. The goal is to determine the best fitness solution available at the end of each iteration to seek a better solution in the process. In general, the three major swarm factors:

1) Population Size is the particle count. A large count of the particle may reduce the count of the iterations required essential for the optimal solution and vice versa.

2) Iteration Number is one of the main parameters for achieving a successful outcome. More iterations make the process complicated and take more time.

3) Acceleration Coefficients $(\mathrm{C} 1 \& \mathrm{C} 2)$ maintain the stochastic impact of social and cognitive components of particle speed respectively. The confidence of the particles in themselves is $\mathrm{C} 1$, while the confidence of the particle in its neighbor is $\mathrm{C} 2$.

The chosen parameters are key in the performance as shown in Table 3:

Table 3: Parameters Settings for PSO

\begin{tabular}{cc}
\hline Parameters & Values \\
\hline Population size & 100 \\
\hline Number of iterations & 500 \\
\hline Acceleration constant, C1 & 2 \\
\hline Acceleration constant, C2
\end{tabular}

The searching procedures of the proposed PSO algorithm are shown below in Fig.9. 


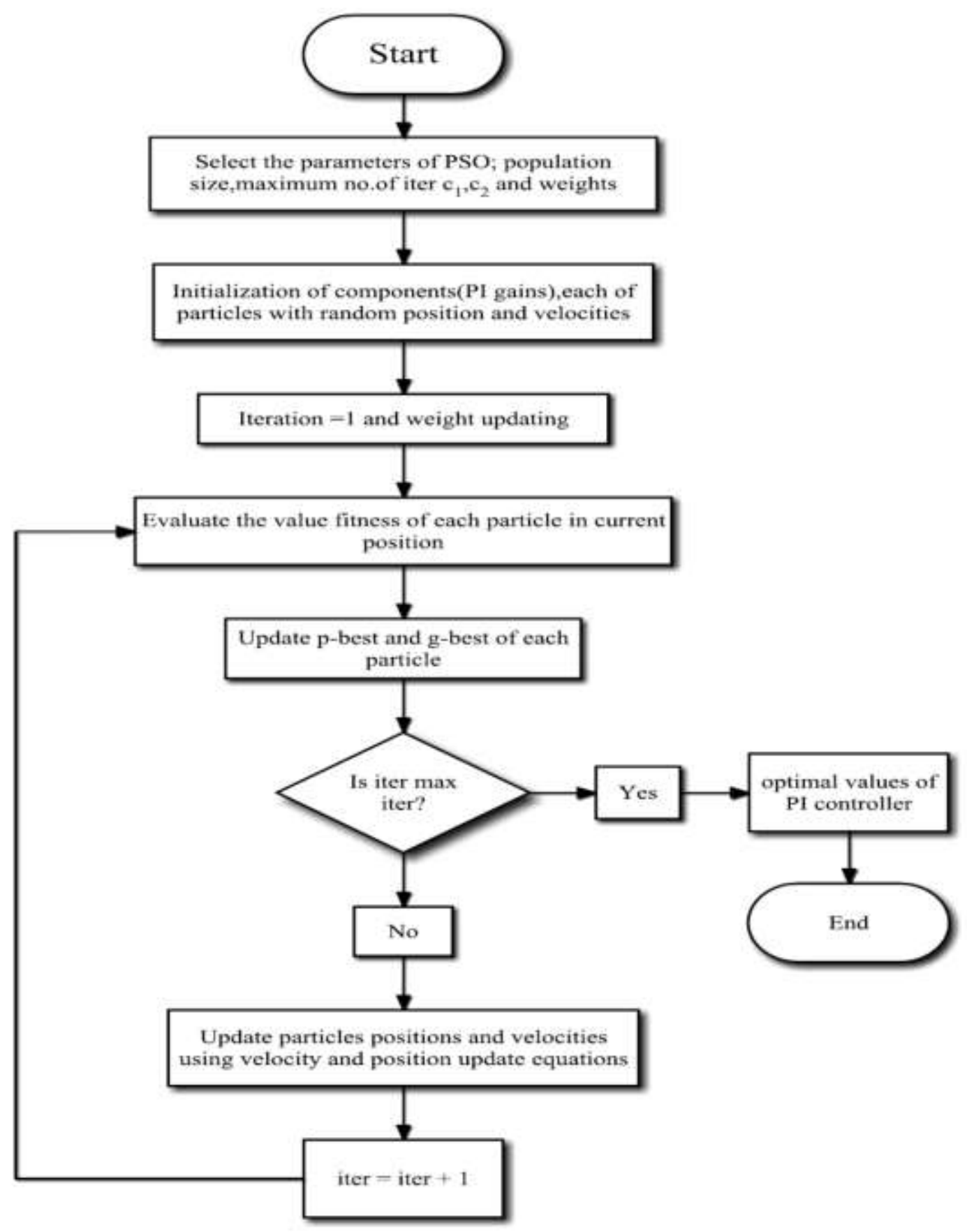

Fig. 9: Flow Chart of the General PSO Algorithm.

\subsubsection{Harmony Search (HS)}

HS is a meta-heuristic optimization that depends on the improvisation process when musicians are looking for a better harmony [23]. Conceptualization of the use of the musical method to achieve optimal harmony was developed. Challenging of applying the algorithm for Harmony Search was very successful to achieve an optimal solution. Diversification is accomplished in the HS algorithm by generating a new solution matching a note. HS has some factors:

1) Harmony memory (HM) has been stored in a fixed number of harmonies. 
r) Harmony Memory considering Rate( HMCR) would determine the likelihood that the value of the original stored values in the HM. If this rate is too poor, there will be just a few elite harmonies chosen. Each element of HM's is chosen to act as pitch-adjusted.

3) Pitch adjustment (PAR) Small value is typically taken. Since, as a very significant element, PAR is essential for convergence. The local search mechanism that governs the capacity for fine-tuning is PA. The next step is to select a value from the total value set randomly; While PA has a similar function and is restricted. The algorithm can be driven by randomization to explore the entire range and achieve global optimality.

Assumed that the aim is to minimize/maximize a fitness function that is subject to several choices. After taking into account all the current vectors. These factors improve the HS algorithm's versatility and achieve better results as shown in Table 4.

Table 4: Parameters Settings for HS

\begin{tabular}{cc}
\hline Parameters & Values \\
\hline Number of iterations & 500 \\
\hline Harmony Memory Size (HM) & 20 \\
\hline Harmony Memory considering Rate (HMCR) & 0.89 \\
\hline Pitch Adjusting Rate (PAR) & 0.3 \\
\hline Distance bandwidth (BW) & 0.001 \\
\hline
\end{tabular}

After setting the HS parameters, the HM Array, the methodology for the solution of HS Algorithm shown in Fig. 10. 


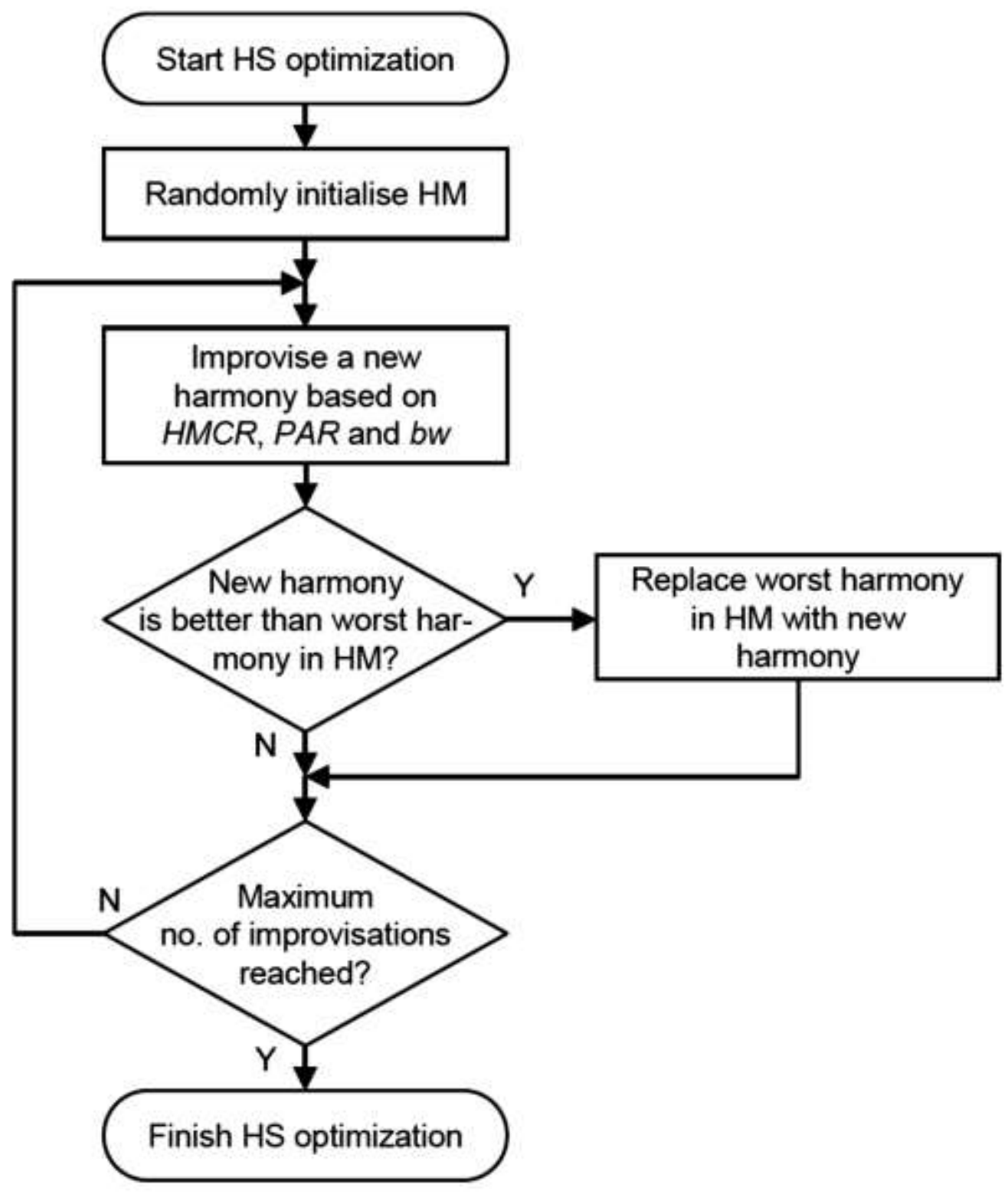

Fig. 10: Flow Chart of the General HS Algorithm.

\subsection{Objective Function (OF)}

Generally, there are many indices applied to assess PI controller performance [24]. This paper describes three objective functions (IAE, ITAE, and ISE) that are compared for tuning purposes. Mathematically, the objective functions are given in equation (1). The idea of its Configuration can also be illustrated by Fig.11.

Integral Absolute Error $(\mathrm{IAE})=\int|\mathrm{e}| \mathrm{dt}$

(3) [25]

Integral Square Error (ISE) $=\int \mathrm{e}^{2} \mathrm{dt}$

(4) [26]

Integral Time Absolute Error $($ ITAE $)=\int t|\mathrm{e}| \mathrm{dt}$

(5) [27] 


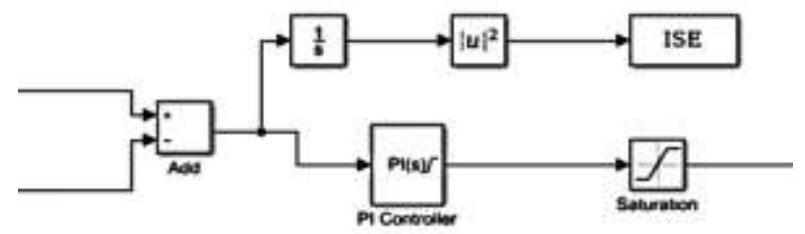

a) The Configuration of ISE for Each PI Controller.

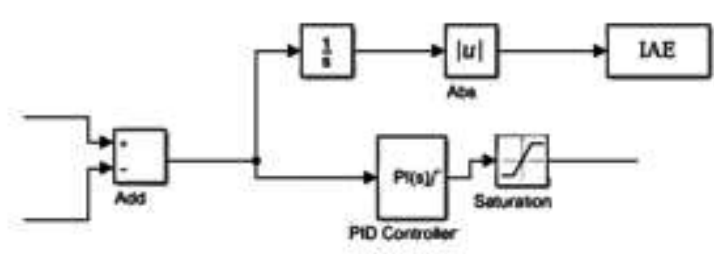

b) The Configuration of IAE for Each PI Controller.

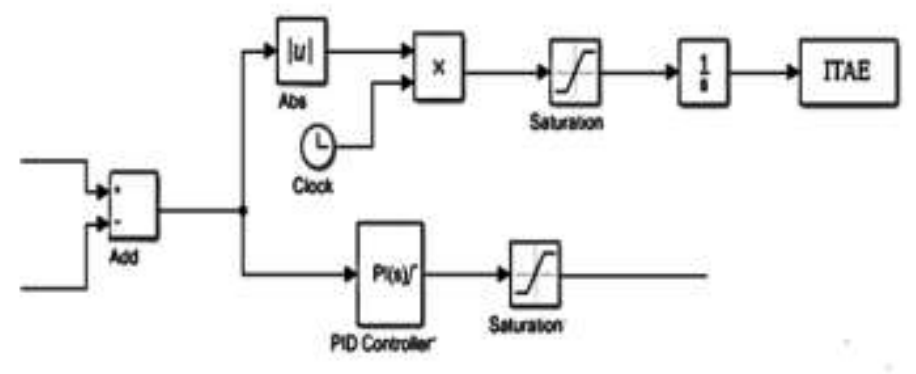

c) The Configuration of ITAE for Each PI Controller.

Fig. 11: Block Diagram of Objective Functions for Each PI Controller.

This paper describes the aspect of the selection of an objective function. The objective function of a problem can be designed easily in simulation programming MATLAB. These objective functions are separately used to determine the fitness value, which is fed into (GA, $\mathrm{PSO}$, and HS) algorithms to obtain optimization parameters of PI controllers. The difference between reference current (Iref) and measured current (Im) is error current $(\Delta \mathrm{I})$.

$$
\Delta \mathrm{I}=\mathrm{Iref}-\mathrm{Im}
$$

Error current for the mentioned above is shown in Fig. 11. The fitness value is found by taking the current error from the simulation of the model and forwarding it to the objective functions. It can be handled the selection of optimum gains ( $\mathrm{Kp}$ and $\mathrm{Ki}$ ) of PI controllers. Their results will be more accurate than the offline tuning technique. This technique is not necessary to solve the equation or computing transfer function to build the current error as in the traditional approach.[28]

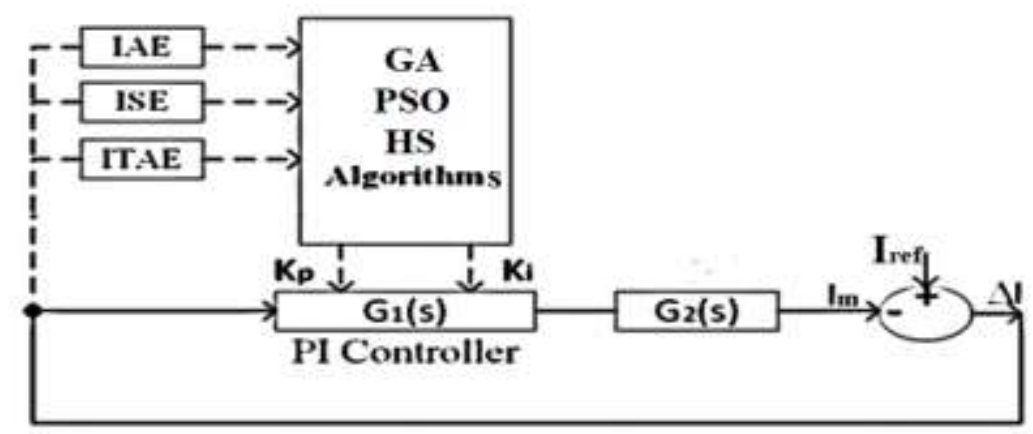

Fig. 12: Feedback control loop. PI control parameter tuning through IAE, ISE, and ITAE.

\section{SIMULATION RESULT}

MATLAB/ SIMULINK is the environment in which the simulation of a system is performed. The tuned PI parameters were tabulated in Table 5 under different proposals. The first proposal a normal case on-grid connected. In the second proposal, the system is moved on- 
grid / off-grid mode at Time $=2 \mathrm{sec}$. The third proposal System exposes three lines to earth fault in an off-grid mode. As such, the algorithms are limited to 500 iterations after that, there was a bit of improvement, according to different algorithms for the implementation of the PI tuning.

Table 5: Adjusted Gain Values of PI Controller

\begin{tabular}{|c|c|c|c|c|c|c|c|c|}
\hline & & \multirow{2}{*}{$\begin{array}{c}\text { PI } \\
\text { No }\end{array}$} & \multicolumn{2}{|c|}{$\mathrm{HS}$} & \multicolumn{2}{|c|}{ GA } & \multicolumn{2}{|c|}{ PSO } \\
\hline & & & $\mathrm{Kp}$ & $\mathrm{Ki}$ & $\mathrm{Kp}$ & $\mathrm{Ki}$ & $\mathrm{Kp}$ & $\mathrm{Ki}$ \\
\hline \multirow{12}{*}{ DG1 } & Normal & & 1 & 0.1 & 1 & 0.1 & 1 & 0.1 \\
\hline & On-grid / off-grid & 1 & 0.96 & 0.101 & 1.04 & 0.092 & 1.1682 & 0.1004 \\
\hline & Fault & & 0.8 & 0.076 & 1.1 & 0.045 & 3.78 & 0.089 \\
\hline & Normal & & 0.1 & 1 & 0.1 & 1 & 0.1 & 1 \\
\hline & On-grid / off-grid & 2 & 0.118 & 1.06 & 0.118 & 1.18 & 0.1199 & 1.1671 \\
\hline & Fault & & 0.13 & 1.1 & 0.1 & 1 & 0.44 & 0.082 \\
\hline & Normal & & 0.5 & 15 & 0.5 & 15 & 0.5 & 15 \\
\hline & On-grid / off-grid & 3 & 0.5933 & 14.066 & 0.5667 & 14.0667 & 0.4455 & 16.1316 \\
\hline & Fault & & 0.876 & 12 & 0.5321 & 16.32 & 0.2376 & 18.453 \\
\hline & Normal & & 35 & 0.5 & 35 & 0.5 & 35 & 0.5 \\
\hline & On-grid / off-grid & 4 & 34.0667 & 0.5667 & 35.1333 & 0.5133 & 34.3133 & 0.3627 \\
\hline & Fault & & 32 & 0.783 & 21.114 & 0.341 & 23.023 & 0.546 \\
\hline \multirow{12}{*}{ DG2 } & Normal & & 0.05 & 5 & 0.05 & 5 & 0.05 & 5 \\
\hline & On-grid / off-grid & 5 & 0.0433 & 4.0667 & 0.0433 & 4.3333 & 0.0596 & 5.5269 \\
\hline & Fault & & 0.0768 & 2.45 & 0.04 & 5.421 & 0.0542 & 5 \\
\hline & Normal & & 0.1 & 2 & 0.1 & 2 & 0.1 & 2 \\
\hline & On-grid / off-grid & 6 & 0.114 & 1.32 & 0.118 & 1.88 & 0.108 & 1.4052 \\
\hline & Fault & & 0.34 & 0.22 & 0.1 & 1 & 0.1 & 1.657 \\
\hline & Normal & & 0.8 & 25 & 0.8 & 25 & 0.8 & 25 \\
\hline & On-grid / off-grid & 7 & 0.7 & 26.466 & 0.62 & 24.0667 & 0.6847 & 26.1949 \\
\hline & Fault & & 0.55 & 27 & 0.84 & 21.436 & 0.75 & 29.21 \\
\hline & Normal & & 35 & 0.01 & 35 & 0.01 & 35 & 0.01 \\
\hline & On-grid / off-grid & 8 & 34.0667 & 0.0163 & 36.2 & 0.0163 & 35.3478 & 0.0123 \\
\hline & Fault & & 33 & 0.023 & 33.432 & 0.03 & 38 & 0.008 \\
\hline \multirow{12}{*}{ DG3 } & Normal & & 0.5 & 0.1 & 0.5 & 0.1 & 0.5 & 0.1 \\
\hline & On-grid / off-grid & 9 & 0.4333 & 0.0993 & 0.4333 & 0.0993 & 0.4184 & 0.0945 \\
\hline & Fault & & 0.403 & 0.1435 & 0.365 & 0.32 & 0.165 & 0.0678 \\
\hline & Normal & & 0.1 & 0.05 & 0.1 & 0.05 & 0.1 & 0.05 \\
\hline & On-grid / off-grid & 10 & 0.1087 & 0.0567 & 0.1087 & 0.0567 & 0.1001 & 0.0526 \\
\hline & Fault & & 0.098 & 0.034 & 0.11 & 0.0532 & 0.34 & 0.08 \\
\hline & Normal & & 0.5 & 10 & 0.5 & 10 & 0.5 & 10 \\
\hline & On-grid / off-grid & 11 & 0.5667 & 8 & 0.5667 & 11.2 & 0.3276 & 8.6556 \\
\hline & Fault & & 0.7 & 3.065 & 0.7423 & 10 & 0.341 & 12.435 \\
\hline & Normal & & 10 & 0.1 & 10 & 0.1 & 10 & 0.1 \\
\hline & On-grid / off-grid & 12 & 10.1333 & 0.094 & 11.2 & 0.0927 & 10.0421 & 0.1008 \\
\hline & Fault & & 8.54 & 0.2 & 9.6822 & 0.1 & 12.5 & 0.42 \\
\hline
\end{tabular}

After the adjustment was made through GA, PSO, and HS algorithms technology, a step change analysis was performed, assisted by the application of the simulation environment. Compare time field specifications for models obtained with the designed controller.

This section introduces the most significant aspect of the simulation. Figures 13-19. Display the simulated responses of the microgrid of various three DGs with different PI controller settings. The process response was observed by giving simulated results where switching from on-grid to off-grid is expressed at $t=2 \mathrm{sec}$. For each DG, the output terminal voltage (Vd), 
(Vq) is shown in Fig. 13, 14. Changes in active and reactive power P (DGS) and Q (DGS) are shown in Fig. 15, 16. DEGs feed local loads, which absorb the active and reactive powers Ploads and Qloads are shown in Fig. 17, 18.

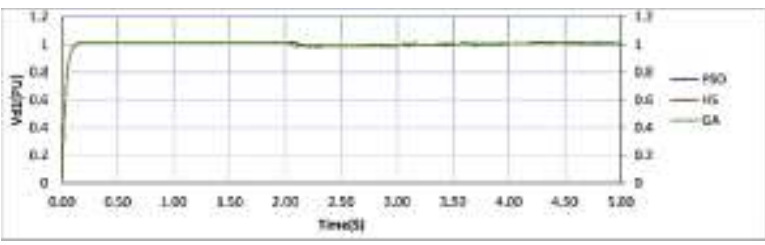

a) The Direct Axis Voltage Vd Of DG1

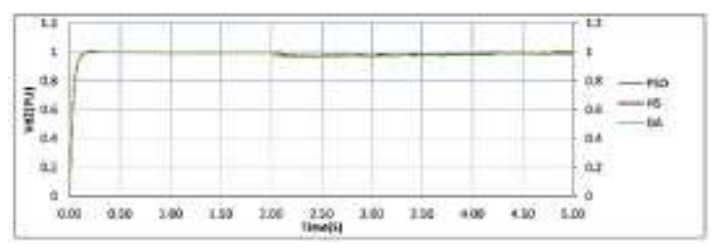

b) The Direct Axis Voltage Vd Of DG2

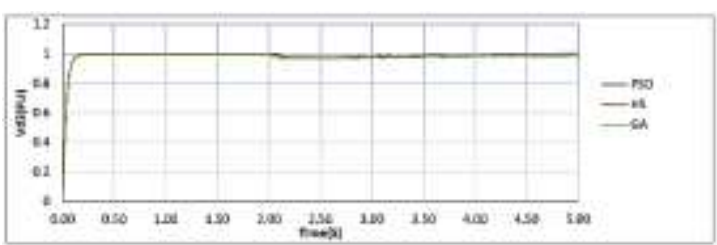

c) The Direct Axis Voltage Vd Of DG3

Fig. 13: The Output Terminal Voltage Vd

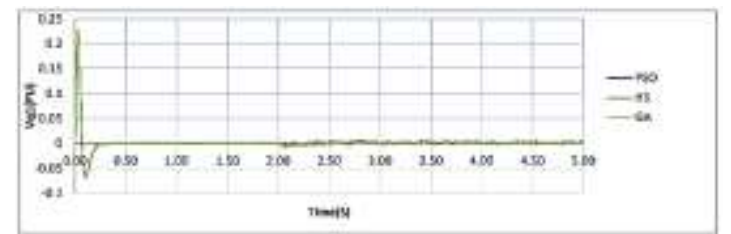

a) The Quadrature Axis Voltage Vq Of DG1

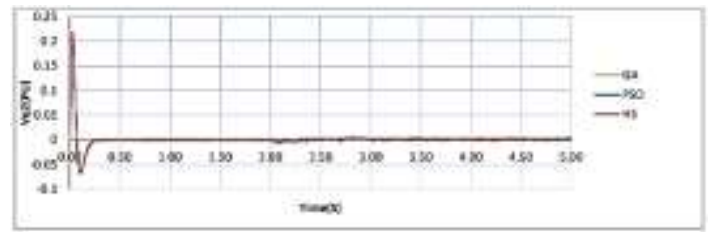

b) The Quadrature Axis Voltage Vq Of DG2

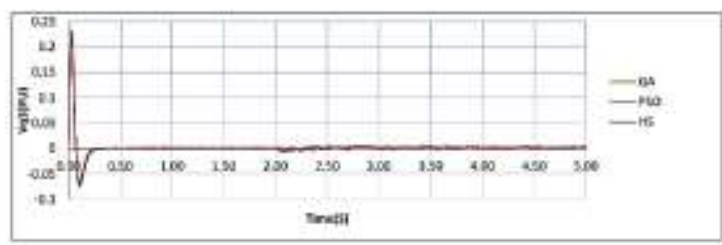

c) The Quadrature Axis Voltage Vq Of DG3

Fig. 14: The Output Terminal Voltage Vq

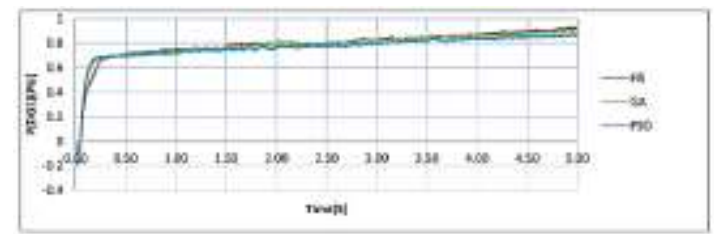

a) Active Power of The DG1.

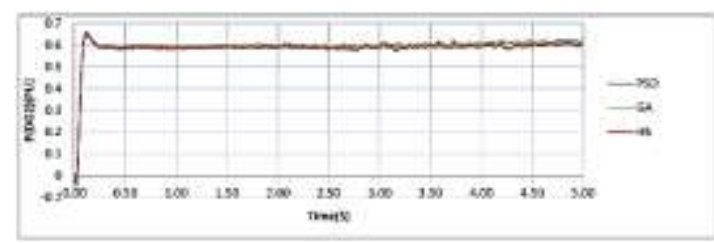

b) Active Power of The DG2.

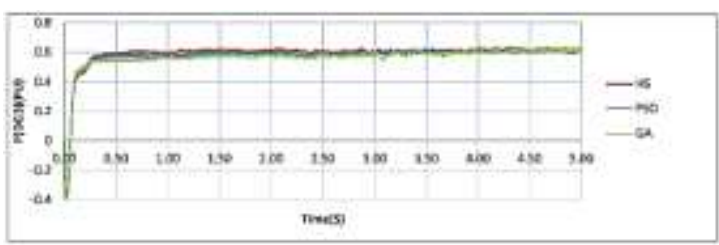

c) Active Power of the DG

Fig. 15: The Active power. 
Evolutionary Algorithms Based tuning PI Controller for Optimal Microgrid Operation

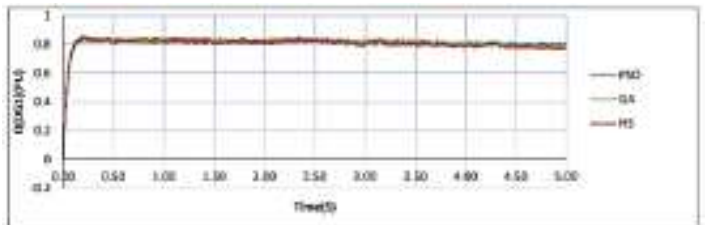

a) Reactive Power of the DG1.

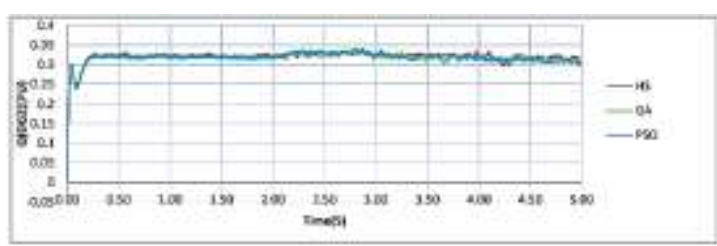

b) Reactive Power of the DG2.

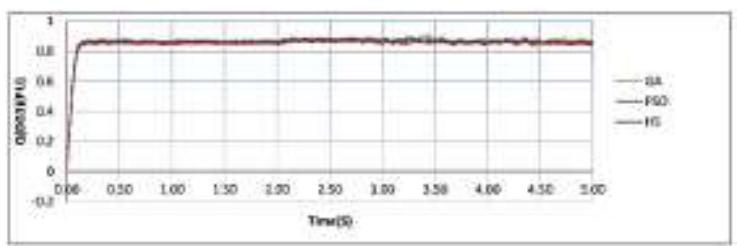

c) Reactive Power Of The DG3

Fig. 16: The Reactive Power

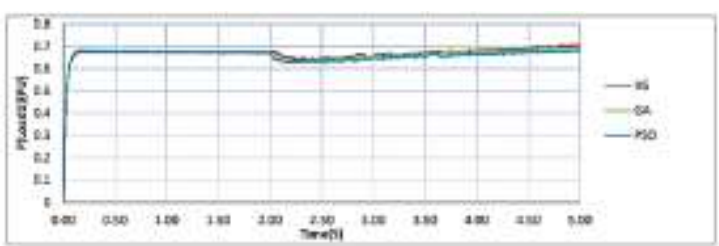

a) Active Power Consumed By The Load At DG1

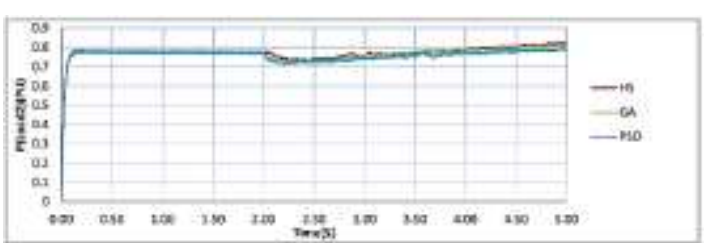

b) Active Power Consumed By The Load At DG2

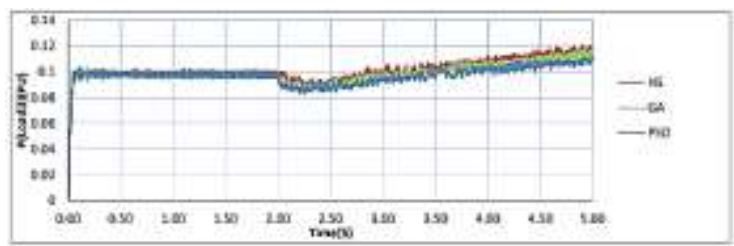

c) Active Power Consumed by The Load At DG3

Fig. 17: Active Power Consumed by The Loads

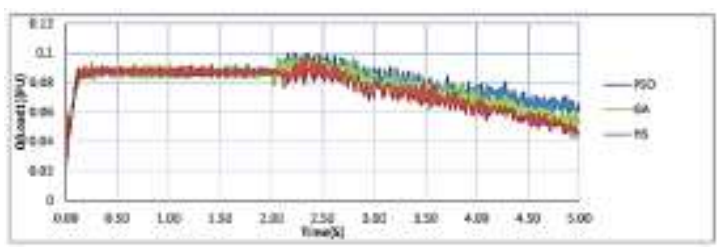

a) Reactive Power Consumed by The Load at DG

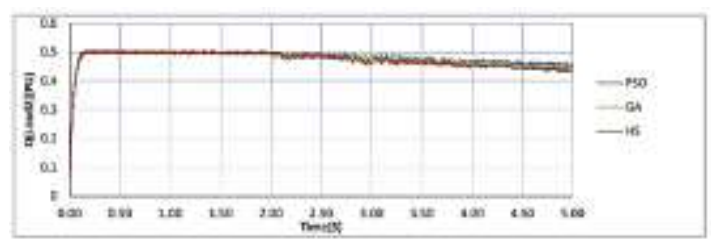

b) Reactive Power Consumed by The Load at DG2

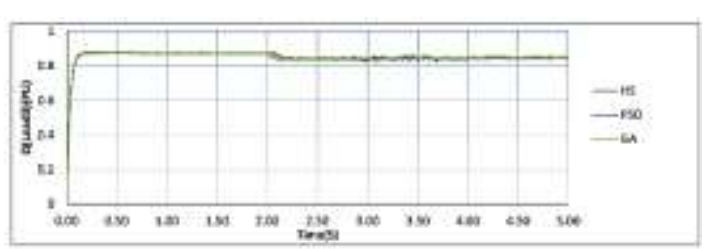

c) Reactive Power Consumed by The Load at DG3

Fig. 18: Reactive Power Consumed By The Loads 
Evolutionary Algorithms Based tuning PI Controller for Optimal Microgrid Operation

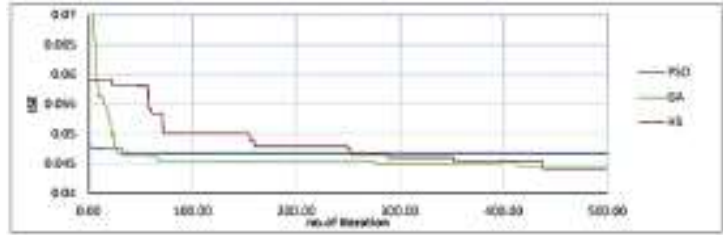

a) The Shape of ISE With No.of Iteration

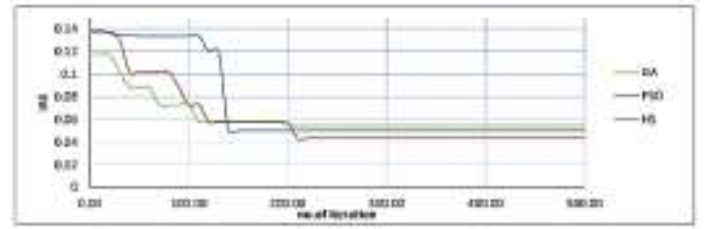

b) The Shape of IAE With No.of Iteration

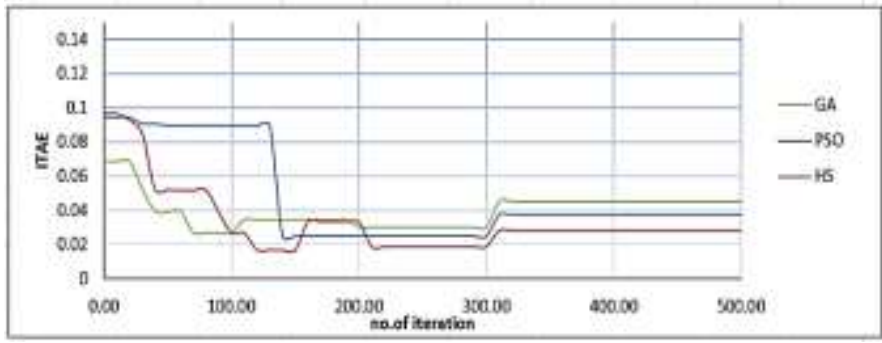

c) The Shape of ITAE With No. of Iteration

Fig. 19: Convergence Graphs of Simulation-Based Objective Function using (PSO, GA, HS) Algorithm.

From the above figures, it is clear that the system using the indicated (PSO, GA, HS) methods include the disturbances at $2 \mathrm{~s}$ as a result of opening C.B at the change from grid to standalone mode:

1- For both (d, q) axis as Fig.13, 14 the system turn back to the ideal value. HS is the fast response on the disturbance but slow to return to balance to ensure safe operation.

2- Fig. 15. Increase active power of DG1 and DG2\&3 keep the same value after variation.

3- Fig. 16. Decrease reactive power of DG1, 2, 3.

4- Fig. 17. Increase consumed active power by the load by a small tolerance value $\approx 2 \%$.

5 - Fig. 18. Decrease reactive power consumed by the load by a small tolerance value $\approx 2 \%$.

6- Fig 19 show the comparison of the objective function ISE, IAE, and ITAE. The HS algorithm performs well in minimizing the error than GA, and PSO.

Table 6: Summary of Comparative Results

\begin{tabular}{|c|c|c|c|c|}
\hline & Performance & HS & GA & PSO \\
\hline \multirow{4}{*}{$\begin{array}{l}\text { On-grid / } \\
\text { off-grid }\end{array}$} & Minimum Percentage Undershoots (MPUS) & $14.265 \%$ & $14.2 \%$ & $14.25 \%$ \\
\hline & Maximum Percentage Overshoots (MPOS) & \multicolumn{3}{|c|}{ Not considered. } \\
\hline & settling time (Ts) & $1.83 \mathrm{~s}$ & $2 \mathrm{~s}$ & $1.92 \mathrm{~s}$ \\
\hline & steady-state error (Ess) & $0.75 \%$ & $0.95 \%$ & $0.834 \%$ \\
\hline \multirow{4}{*}{ Fault } & Minimum Percentage Undershoots (MPUS) & $96.8216 \%$ & $96.8 \%$ & $96.82 \%$ \\
\hline & Maximum Percentage Overshoots (MPOS) & $6.5 \%$ & $5.342 \%$ & $5.98 \%$ \\
\hline & settling time (Ts) & $2.6 \mathrm{~s}$ & $2.67 \mathrm{~s}$ & $2.8 \mathrm{~s}$ \\
\hline & steady-state error (Ess) & $1.5 \%$ & $1.76 \%$ & $1.64 \%$ \\
\hline
\end{tabular}




\section{CONCLUSIONS}

This paper has illustrated the DEG system optimal control enhances the system to make stability and flexibility. PI controller parameters tuned for level control application under three dissimilar operation proposals. The first applied are on-grid, the second one is converted on-grid connected to off-grid connected, and three phases to earth fault occurrence during offgrid. Three meta-heuristic algorithms HS, GA, and PSO. These techniques are used for optimal design procedures for tuning PI controller parameters. They were compared to assess the design quality of the different DEGs. Three comparative methods were demonstrated concerning population size, and the number of iterations, and reduced ISE, IAE, and ITAE. MATLAB/ SIMULINK is the emulation software used. It inferred that while these algorithms do the same optimal minimum solution, the HS performance is more efficient than GA and PSO, which will influence the behavior of the DEGs.

\section{REFERENCES}

1. P. Kundur and C. Taylor, (2007). Blackout experiences and lessons best practices for system dynamic performance the role of new technologies. The Institute of Electrical and Electronic Engineers, Inc.

2. G. Pepermans and others, 2005. Distributed generation: Definition, benefits and issues, Energy Policy, Elsevier, vol. 33, pp. 787-798.

3. Hongwei Ren, Congying Han, Tiande Guo, and Wei Pei, 2014. Energy Losses and Voltage Stability Study in Distribution Network with Decentralized energy generation, Journal of Applied Mathematics, vol.23.

4. P. K. Modi1, S. P. Singh2, J. D. Sharma2 and P. K. Pradhan3, 2006. Stability improvement of power system by decentralized energy. Advances in Energy Research (AER)., pp. 65- 70.

5. S. M.Muyeen,M. Hasan Ali, R. Takahashi, T.Murata, J. Tamura,M. Kubo, A. Kuwayama, and T. Matsumoto, 2009. Low voltage ride through capability enhancement of wind turbine generator system during network disturbance. IET Renew. Power Generation, vol. 3, no. 1, pp. 65-73.

6. Edjadéssamam AKORO, Marie Emilienne FAYE, Moustapha SENE, Gabriel jean Philipe TEVI and Amadou SEIDOU MAIGA, 2017. Differents topologies of threephase grid connected inverter for photovoltaic systems, a review. Sciences Appliquées et de l'Ingénieur, vol. 2, no. 2, ISSN 2312-8712.

7. E. Muljadi, C. P. Butterfield, B. Parsons, and A. Ellis, 2007. Effect of variable speed wind turbine generator on stability of a weak grid. IEEE Trans. Energy Convers., vol. 22, no. 1, pp. 29-36.

8. K Smriti Rao, Ravi Mishra,2014. Comparative study of P, PI and PID controller for speed control of VSI-fed induction motor. IJEDR ., Vol. 2, no. 2

9. Gandomi, A. H., Alavi, A. H, 2011. Applications of computation intelligence in behaviour simulation of concrete maerials. Computational Optimization and Applications in Engineering and Industry (Eds. X. S. Yang and S. Koziel), Springer SCI 359, 221-243.

10. Blum, C. and Roli, 2003. Metaheuristics in combinatorial optimization: Overview and conceptural comparision. ACM Comput. Surv., 35 , 268-308.

11. Liqun Liu, Jiuyuan Huo, Fei Xue and Yongqiang Dai, 2020. Harmony Search Method with Global Sharing Factor Based on Natural Number Coding for Vehicle Routing Problem, Information, MDPI.

12. Krzysztof Drachal, Michał Pawłowski, 2021. A Review of the Applications of Genetic Algorithms to Forecasting Prices of Commodities, Economies, MDPI.

13. Ovat Friday Aje, Anyandi Adie Josephat, 2020. The particle swarm optimization (PSO) algorithm application - A review, Global Journal of Engineering and Technology Advances, 03, 001-006. 
14. Andreas Antoniou and Wu-Sheng Lu, 2007 . Practical Optimization Algorithms and Engineering Applications, Springer.

15. Altera. Hardware in the Loop from the MATLAB/Simulink Environment. 2017.Available online: https://www. altera.com/en_US/pdfs/literature/wp/wp-01208hardware-in-the-loop.

16. B. Wen, D. Dong, D. Boroyevich, R. Burgos, P. Mattavelli, and Z. Shen, Jan. 2016. "Impedance-based analysis of grid-synchronization stability for three-phase paralleled converters," IEEE Trans. Power. Electron., vol. 31, no. 1, pp. 26-38.

17. Dina A. Zaki, Hany M. Hasanien, Noha H. El-Amary, AY Abdelaziz, 2017. Crow Search Algorithm for Improving the Performance of an Inverter- Based Distributed Generation System". Nineteenth International Middle East Power Systems Conference (MEPCON), Menoufia University, Egypt 19-21.

18. F. Katiraei and M. R. Iravani, 2006. Power management strategies for a microgrid with multiple distributed generation units. IEEE Trans. Power Syst., vol. 21, no. 4, pp. $1821-1831$.

19. A. H. Etemadi, E. J. Davison, and R. Iravani, 2012. A decentralized robust control strategy for multi-DER microgrids - Part I: Fundamental concepts. IEEE Trans. Power Del., vol. 21, no. 4.

20. N. Hatziargyriou, H. Asano, R. Iravani, and C. Marnay, 2007. Microgrids, Power and Energy Magazine, IEEE, vol. 5, no. 4, pp. 78-94.

21. T. S. Basso and R. DeBlasio, 2004. Ieee 1547 series of standards: interconnection issues. Power Electronics, IEEE Transactions on, vol. 19, no. 5, pp. 1159-1162.

22. J. J. Greffenstette. Optimization of control parameters for genetic algorithms, 1986. IEEE Transactions on Systems, Man, and Cybernetics SMC16, pages 122-128.

23. A. Popov and K. Filipova, 2004. Genetic algorithms-synthesis of finite state machines. Electronics Technology: Meeting the Challenges of Electronics Technology Progress. 27th International Spring Seminar on, vol. 3. IEEE, pp. 388-392.

24. Liu, C. H., \& Hsu, Y. Y. (2010). Design of a self-tuning PI controller for a STATCOM using particle swarm optimization. IEEE Transactions on Industrial Electronics, vol.57, no.2, 702-715.

25. Haaris Rasool, Aazim Rasool, Ataul Aziz Ikram , Urfa Rasool, Mohsin Jamil , and Haaziq Rasool,2019. Compatibility of objective functions with simplex algorithm for controller tuning of HVDC system. Ingenier' ia e investigacion' vol. 39 no. 3, pp. 3443.

26. Pavel Zítek, Jaromír Fišer, Tomáš Vyhlídal, 2016. IAE Optimization of PID Control Loop with Delay in Pole Assignment Space. International Federation of Automatic Control, vol. 49, no.10, pp. 177-181.

27. S.L. Kang, Z.W. Geem, 2015. A new structural optimization method based on the harmony search algorithm", Comput. Struct. vol 82 (9-10), pp.781-798.

28. Fernando G. Martins,2005. Tuning PID Controllers using the ITAE Criterion. Int. J. Engng Ed. vol. 21, no. 5, pp. 867-873. 